\title{
Douvaine - Avenue de Genève
}

\section{Franck Gabayet}

\section{OpenEdition \\ Journals}

Édition électronique

URL : http://journals.openedition.org/adlfi/14907

ISSN : 2114-0502

Éditeur

Ministère de la culture

\section{Référence électronique}

Franck Gabayet, "Douvaine - Avenue de Genève », ADLFI. Archéologie de la France - Informations [En ligne], Rhône-Alpes, mis en ligne le 28 mai 2015, consulté le 01 mai 2019. URL : http:// journals.openedition.org/adlfi/14907

Ce document a été généré automatiquement le 1 mai 2019.

(c) Ministère de la Culture et de la Communication, CNRS 


\title{
Douvaine - Avenue de Genève
}

\author{
Franck Gabayet
}

Code INSEE de la commune : 74105

Lien Atlas (MCC) :

http://atlas.patrimoines.culture.fr/atlas/trunk/index.php?

ap_theme=DOM_2.01.02\&ap_bbox=6.273;46.289;6.328;46.326

1 L'opération de diagnostic de Douvaine, avenue de Genève, au lieu-dit La Barque, s'est déroulée du 21 au 23 janvier 2013, sous la conduite d'une équipe de deux archéologues de l'Inrap. Dix-neuf sondages ont pu être réalisés sous la forme de tranchées d'environ $17 \mathrm{~m}$ de long pour une largeur constante de $1,80 \mathrm{~m}$.

En dépit de mentions nombreuses de vestiges sur le territoire de la commune de Douvaine, tombes de l'âge du Bronze et de l'âge du Fer, découvertes de mobilier antique, dédicace à une divinité auguste ou encore coffrages de dalles alto-médiévaux, force est de constater que les sondages peuvent être qualifiés de négatifs.

Une unité stratigraphique permet tout au plus de restituer un vague horizon d'une épaisseur de l'ordre de 0,30 m qui livre quelques résidus de terres cuites architecturales, probablement des fragments de tuiles ou de briques antiques. Un unique tesson de céramique noire non tournée ne suffit pas à préciser la chronologie.

\section{INDEX}

Index géographique : Rhône-Alpes, Haute-Savoie (74), Douvaine

operation Opération préventive de diagnostic (OPD), 2013 - n OA : 2211101

Mots-clés : céramique 
AUTEURS

FRANCK GABAYET

Inrap 